\title{
A DECADE OF ARCHITECTURAL AND URBAN RESEARCH PUBLISHED IN 'ARCHNET-IJAR: INTERNATIONAL JOURNAL OF ARCHITECTURAL RESEARCH'
}

\author{
Ashraf M. Salama, * Adel M. Remali, and Farzad Pour Rahimian \\ Department of Architecture, University of Strathclyde, Glasgow, United Kingdom
}

*ashraf.salama@strath.ac.uk - asalama@gmail.com

\begin{abstract}
This article commemorates a decade of discourse and published research on architecture and urbanism in ArchNet-IJAR (March 2007-March 2017). While the journal does not publish regular editorials associating each issue, it is believed that offering key highlights of growth since the inception of the journal is now due. The article presents the current position of ArchNet-IJAR within the international provision of journals in architecture and urban studies in key databases and index-bases. This is substantiated by key statistics of submissions, published contributions, and acceptance rates during the past 10 years. Coupled with analytical discussion on the global reach of the ArchNet-IJAR, the article identifies 11 research fields, which were covered in 10 volumes since the journal's inception. Analytical discussions of recent two theme issues as well as latest developments and contributions during the past few years are presented to reflect on the rigor and quality of the journal while depicting its thrust and interest. The article concludes by key aspects relevant to the future aspirations of ArchNet-IJAR while highlighting initiatives and prospective endeavours.
\end{abstract}

Keywords: architecture; architectural design; architectural education; IT in design and construction; online publishing; open access journals; sustainable design; urban design; urban planning; urbanism

\section{INTRODUCTION: CURRENT POSITION OF ARCHNET-- IJAR}

Over the past decade and since ArchNet-IJAR has published its first issue in March 2007 the journal has managed to position itself on the map of open access publishing in architecture and urbanism. Since the journal does not publish regular editorials associating each issue, it is believed offering key highlights of developments is important, given that ArchNet-IJAR celebrates the completion of a decade of discourse and published research on architecture and urbanism.

Following a comprehensive process of academic review of articles and research work submitted to the journal, it has succeeded to secure its position in various databases with three main unique features that can be outlined as follows:

- ArchNet-IJAR aims to offer the opportunity to young academics, PhD scholars, reaching across the boundaries of generations, cultures, and regions.

- ArchNet-IJAR was, and still is, based on voluntary work including the work of its editors and reviewers where no funds are involved in managing, reviewing, or editing the submissions before or after publishing.

- ArchNet-IJAR since the beginning was, and still is, made available for free without subscription fees or publishing fees.

While current challenges mandate alternative approaches to online publishing, establishing an understanding of the significant contributions the journal has made is important to note. These contributions come from authors, advisory and editorial boards, as well as the editorial team. Ashraf M. Salama, the founder of ArchNet-IJAR, continues to lead the journal since its inception in 2006, manages all content related issues as well as final reviews and production, in addition to undertaking key tasks and special issues with support from the two associate editors: Farzad Pour Rahimian and Remah Y. Gharib. Notably, a multi-generational cohort of scholars ranging 
from well established academics and international figures to young researchers are behind the success the journal has made over the past decade.

In 2014, ArchNet-IJAR was included in Quartile 2 (Q2) list of Journals both in 'Architecture' and 'Urban Studies.' Since rankings and measures are calculated based on the preceding year, as of May 2015, ArchNet-IJAR was ranked 23 out of 83 journals in 'Architecture' and 59 out of 119 in 'Urban Studies.' Rankings are based on the SJR (SCImago Journal Ranking); an indicator that measures the scientific influence of the average article in a journal. SJR is a measure of scientific influence of scholarly journals that accounts for both the number of citations received by a journal and the importance or prestige of the journals where such citations come from. These figures have slightly progressed in 2016 where IJAR was ranked 23 out of 111 journals in 'Architecture' and 63 out of 127 in 'Urban Studies' (Figure 1). See here for more information (http://www.scimagojr.com/index.php) and (http://www.journalmetrics.com/sjr.php).

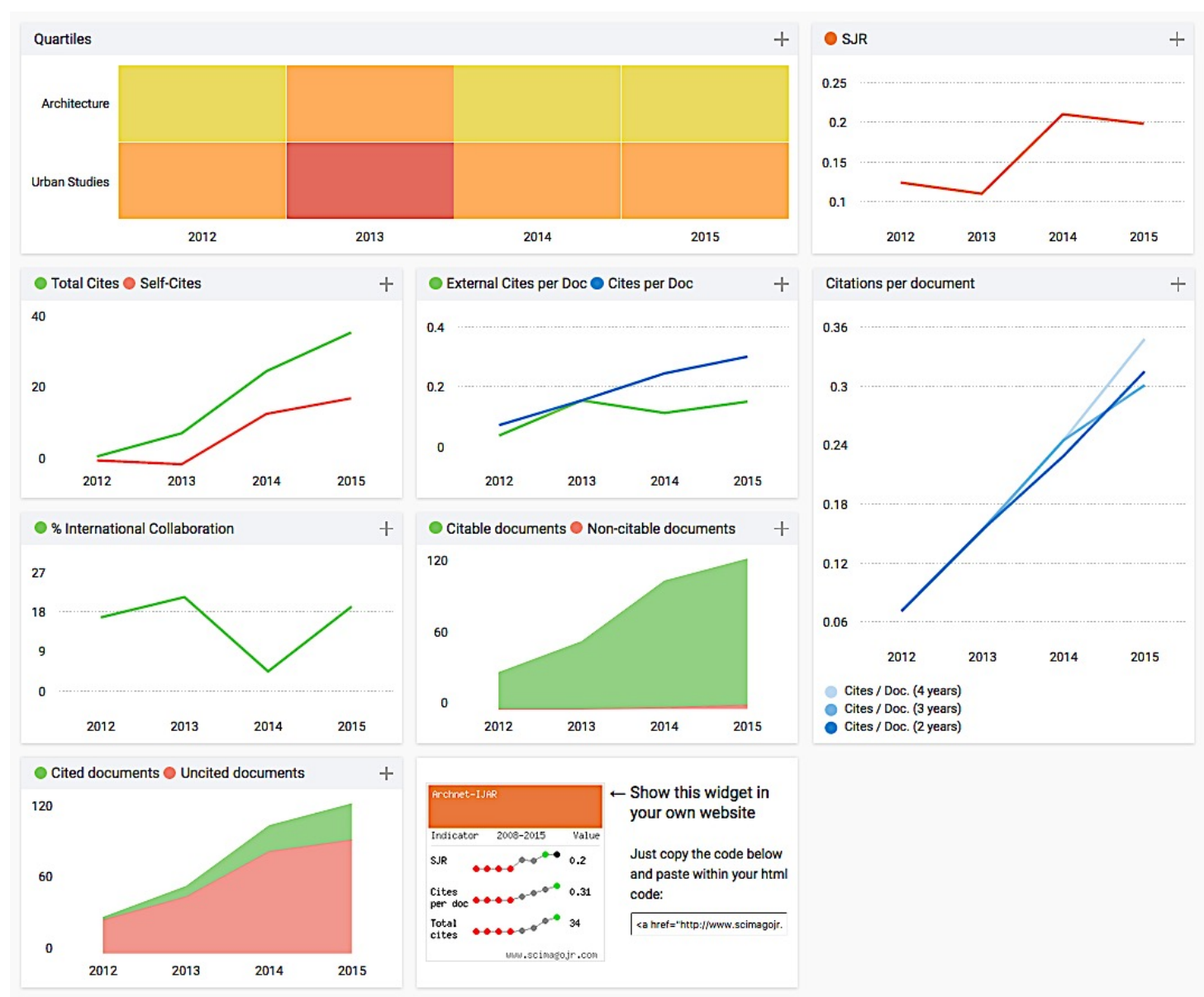

Figure 1: Key features of ArchNet-IJAR rankings in SCImago Journal Rankings as of May 2015.

The figure illustrates SJR measure, quartiles, and citation records

(Source: http://www.scimagojr.com/journalsearch.php?q=21100201015\&tip=sid\&clean=0).

According to the CiteScore ranks and trends which are conducted annually by Scopus database and are differentiated from SCImago Journal Ranking, ArchNet-IJAR was ranked in "Architecture" category 39 out of 55 in 2012, 36 out of 64 in 2013, 28 out of 82 in 2014, and 26 out of 84 in 2015 (Figure 2). Based on the current figures in the database, it is anticipated that the ranking will move up several places. While the journal is now on top of many of the distinguished journals in 
Elsevier- Scopus database, it will keep aspiring to sustain and enhance its position while working toward being part of Q1 group list and eventually in the top 10 journal list in the field. However, this requires continuous and augmented efforts and conscious endeavours that give attention to quality submissions with a rigorous review process.
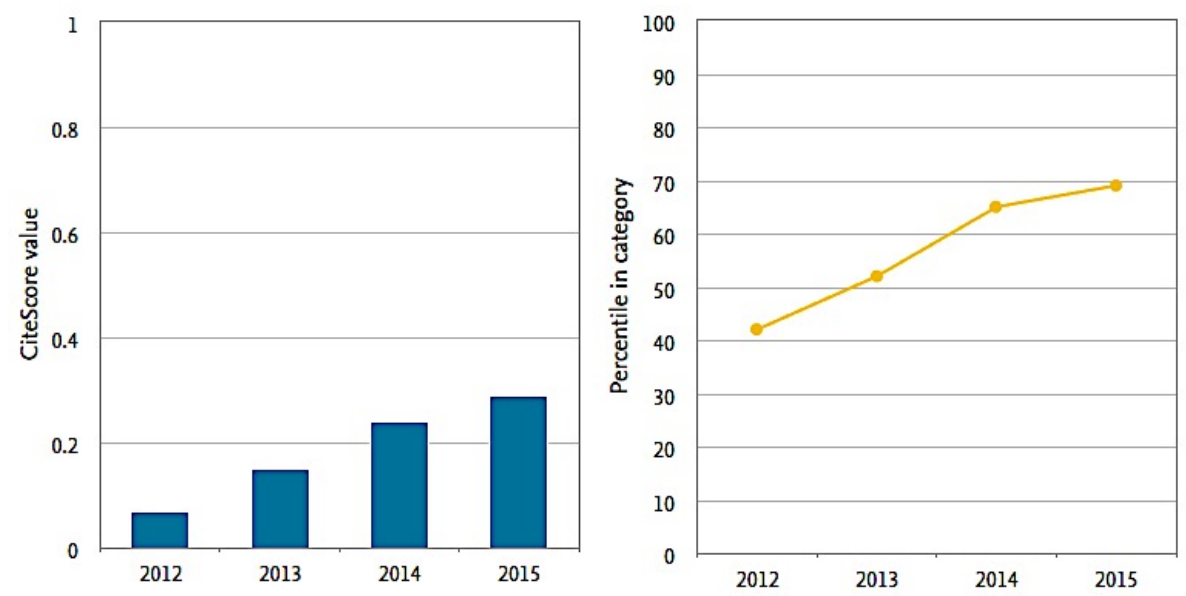

Figure 2: CiteScore and percentile trends of Archnet-IJAR within Scopus Database (Source: http://www.scopus.com -- requires login credentials).

\section{SUBMISSION, ACCEPTANCE RATES, AND TRENDS OF PUBLISHED WORK}

Submissions are typically for the regular section of ArchNet-IJAR, which involves a double reviewing process. In the early years, however, a few submissions were made to the section "reviews and trigger articles" which were typically reviewed by the Chief Editor. Occasionally and based on interest, the journal solicits book review articles from academics in the field that are normally reviewed only by the Chief Editor or the Managing Editor. The total number of papers submitted for peer review over the past decade (March 2007 - January 2017) is 1515 papers while the total number of published papers is 352 during the period reflected an average acceptance rate that does not exceed $30 \%$. The total number of submissions continued to grow significantly, from 31 submissions in 2007 to 334 and 272 in 2015 and 2016 respectively.

Attracting and seizing attention of the international academic community, invited internationally renowned figures such as Amos Rapoport, Henry Sanoff, Nikos Salingaros, Roderick Lawrence, Wolfgang Preiser (Rapoport, 2008; Sanoff, 2008; Salingaros and Masden, 2008; Lawrence, 2008; Preiser, 2008; Preiser and Wang, 2008; Preiser, Verderber and Battisto, 2009; Davis and Preiser 2012) among many other important academics was important to set the stage for high quality in online publishing. The acceptance rates in the years between 2007 and 2010 were somewhat high and reached over $70 \%$ in 2007 and with more organized procedures for review that were introduced gradually acceptance rates were $35 \%$ in 2010 . Recently acceptance rates ranged between $21 \%$ in 2013 and $17 \%$ in 2016 reflecting more strict submission and review procedures. Table (1) illustrates trends of total numbers of submitted and published papers as well as acceptance rates.

\section{GLOBAL REACH OF ARCHNET-IJAR}

ArchNet-IJAR is truly international and has significant global reach as evidenced in the overall profile of its advisory and review boards. Specifically, over the past decade contributions to submissions involving one or more authors came from 58 countries (Figure 3) with highest numbers of contributions came from United States and lowest numbers came from Syria. 
Table 1: A breakdown of peer-reviewed papers submitted to and published in ArchNet-IJAR: International Journal of Architectural Research across volumes since 2007 (Source: Authors).

\begin{tabular}{|c|c|c|c|c|c|c|c|}
\hline Year & Volume & $\begin{array}{l}\text { Issue } \\
1\end{array}$ & Issue 2 & Issue 3 & $\begin{array}{l}\text { Total } \\
\text { Published } \\
\text { Papers }\end{array}$ & $\begin{array}{l}\text { Acceptance } \\
\text { Rate }\end{array}$ & $\begin{array}{l}\text { Total Submitted } \\
\text { Papers }\end{array}$ \\
\hline 2007 & $1^{\mathrm{st}}$ & 7 & 6 & 10 & 23 & $74 \%$ & 31 \\
\hline 2008 & $2^{\text {nd }}$ & 11 & 12 & 12 & 35 & $67 \%$ & 52 \\
\hline 2009 & $3^{\text {rd }}$ & 17 & 7 & 8 & 32 & $59 \%$ & 54 \\
\hline 2010 & $4^{\text {th }}$ & 12 & \multicolumn{2}{|l|}{32} & 44 & $35 \%$ & 125 \\
\hline 2011 & $5^{\text {th }}$ & 10 & 6 & 6 & 22 & $31 \%$ & 71 \\
\hline 2012 & $6^{\text {th }}$ & 6 & 7 & 7 & 20 & $31 \%$ & 65 \\
\hline 2013 & $7^{\text {th }}$ & 13 & 23 & 10 & 46 & $21 \%$ & 223 \\
\hline 2014 & $8^{\text {th }}$ & 12 & 7 & 19 & 38 & $13 \%$ & 288 \\
\hline 2015 & $9^{\text {th }}$ & 20 & 17 & 10 & 47 & $14 \%$ & 334 \\
\hline 2016 & $10^{\text {th }}$ & 21 & 13 & 11 & 45 & $17 \%$ & 272 \\
\hline \multicolumn{5}{|r|}{ Total } & 352 & ----- & 1515 \\
\hline
\end{tabular}

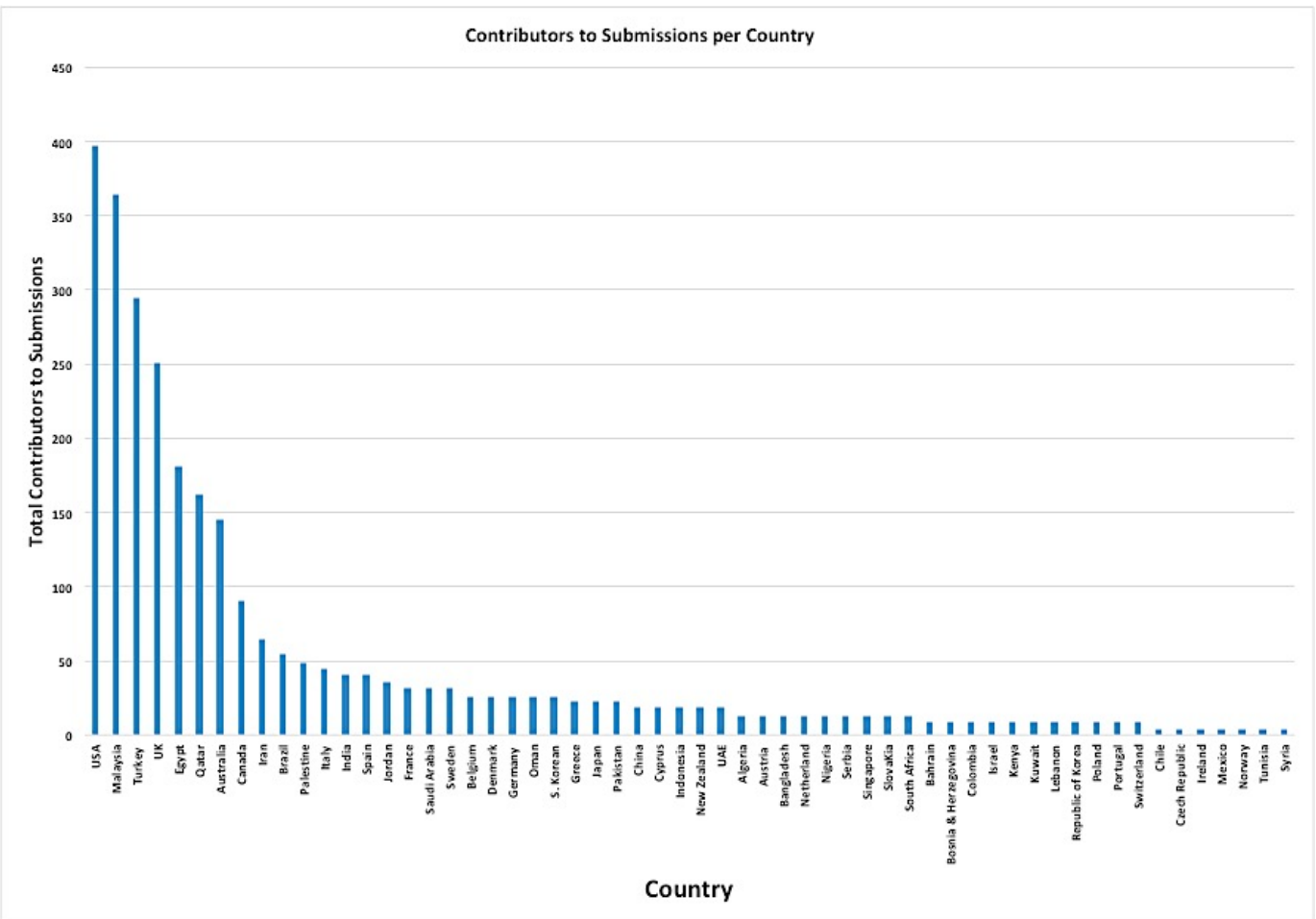

Figure 3: Total numbers of contributions to submissions to Archnet-IJAR 2007-2017 per country (Source: Authors).

The highest contributions to submissions came from 12 countries across the globe, both from the global north and the global south. United States, United Kingdom, Australia, Canada, and Italy appear to have the highest numbers of contributions to submissions in the global north and the English-speaking world, while Malaysia Turkey, Egypt, Qatar, Iran, Brazil, and Palestine have the highest numbers of contributions to submissions in the global south. It is noted that one submission may have contributors from two or more different countries. 
Table 2: A breakdown of the highest number of contributions to submissions to ArchNet-IJAR 2007-2017 (Source: Authors).

\begin{tabular}{ll}
\hline Countries & $\begin{array}{l}\text { Number of } \\
\text { Contributions } \\
\text { to } \\
\text { Submissions }\end{array}$ \\
\hline USA & 397 \\
\hline Malaysia & 364 \\
\hline Turkey & 294 \\
\hline UK & 251 \\
\hline Egypt & 181 \\
\hline Qatar & 162 \\
\hline Australia & 145 \\
\hline Canada & 90 \\
\hline Iran & 64 \\
\hline Brazil & 55 \\
\hline Palestine & 49 \\
\hline Italy & 45 \\
\hline
\end{tabular}

\section{PRIMARY AND SECONDARY RESEARCH FIELDS WITHIN ARCHNET-IJAR}

ArchNet-IJAR objective is to establish a bridge between theory and practice in the fields of architectural and design research, urban planning, and built environment studies. It reports on the latest research findings and innovative approaches for creating responsive environments, with special focus, but not exclusive, on architecture and planning in the global south. ArchNet-IJAR aims at strengthening ties between scholars from different parts of the world with contributors and readers reaching across geographical locations and cultures. The journal publishes research studies, criticisms and critical analyses about the creation, use, and evaluation of different types of environments at the macro and micro scales. ArchNet-IJAR includes original empirical research papers, analytical case studies, and high quality position papers that contribute to the advancement of knowledge in architecture and urbanism within four main areas: architectural and design research, b) urban and built environment studies, c) critical essays on architectural and planning projects and d) reviews and trigger articles.

In order to establish an understanding of the range of research fields within these four areas, a classification of main and secondary fields of each published contribution was undertaken. The classification involved a preliminary content analysis under 11 research fields, listed below, in order of highest frequency, as main research fields, across the volumes and issues since 2007:

1) Architectural Design / Design Analysis

2) Architectural Education \& Professional Practice

3) Building Technology \& Sustainable Design

4) Environment-Behaviour Studies

5) History \& Heritage, 6) Housing

7) IT in Design \& Construction

8) Strategic Thinking \& Visioning

9) Architectural/Urban Theory

10) Urban Design Research

11) Urban Planning \& Sustainable Development 
Table 3: A breakdown of main research fields based on the published articles in ArchNet-IJAR 2007-2017 (Source:

Authors).

\begin{tabular}{|c|c|c|c|c|c|c|c|c|c|c|c|}
\hline & 2007 & 2008 & 2009 & 2010 & 2011 & 2012 & 2013 & 2014 & 2015 & 2016 & Total \\
\hline Architectural Design / Design Analysis & 6 & 10 & 3 & 1 & 2 & 5 & 6 & 15 & 6 & 11 & 65 \\
\hline $\begin{array}{l}\text { Architectural Education \& Professional } \\
\text { Practice }\end{array}$ & 2 & 3 & 3 & 33 & 1 & 3 & 5 & 4 & 1 & 2 & 57 \\
\hline $\begin{array}{l}\text { Building Technology \& Sustainable } \\
\text { Design }\end{array}$ & 3 & 0 & 4 & 0 & 2 & 0 & 4 & 4 & 2 & 1 & 20 \\
\hline Environment-Behaviour Studies & 1 & 4 & 6 & 2 & 2 & 2 & 1 & 4 & 1 & 3 & 26 \\
\hline History \& Heritage & 1 & 11 & 5 & 3 & 2 & 1 & 3 & 2 & 15 & 5 & 48 \\
\hline Housing & 4 & 1 & 6 & 1 & 6 & 0 & 5 & 3 & 6 & 9 & 41 \\
\hline IT in Design \& Construction & 0 & 1 & 0 & 0 & 2 & 0 & 1 & 0 & 9 & 1 & 14 \\
\hline Strategic Thinking \& Visioning & 0 & 0 & 1 & 2 & 1 & 0 & 4 & 2 & 1 & 0 & 11 \\
\hline Architectural/Urban Theory & 5 & 2 & 0 & 1 & 1 & 1 & 2 & 3 & 0 & 1 & 16 \\
\hline Urban Design & 1 & 2 & 1 & 1 & 3 & 6 & 11 & 0 & 5 & 8 & 38 \\
\hline $\begin{array}{l}\text { Urban Planning \& Sustainable } \\
\text { Development }\end{array}$ & 0 & 1 & 3 & 0 & 0 & 2 & 4 & 1 & 1 & 4 & 16 \\
\hline
\end{tabular}

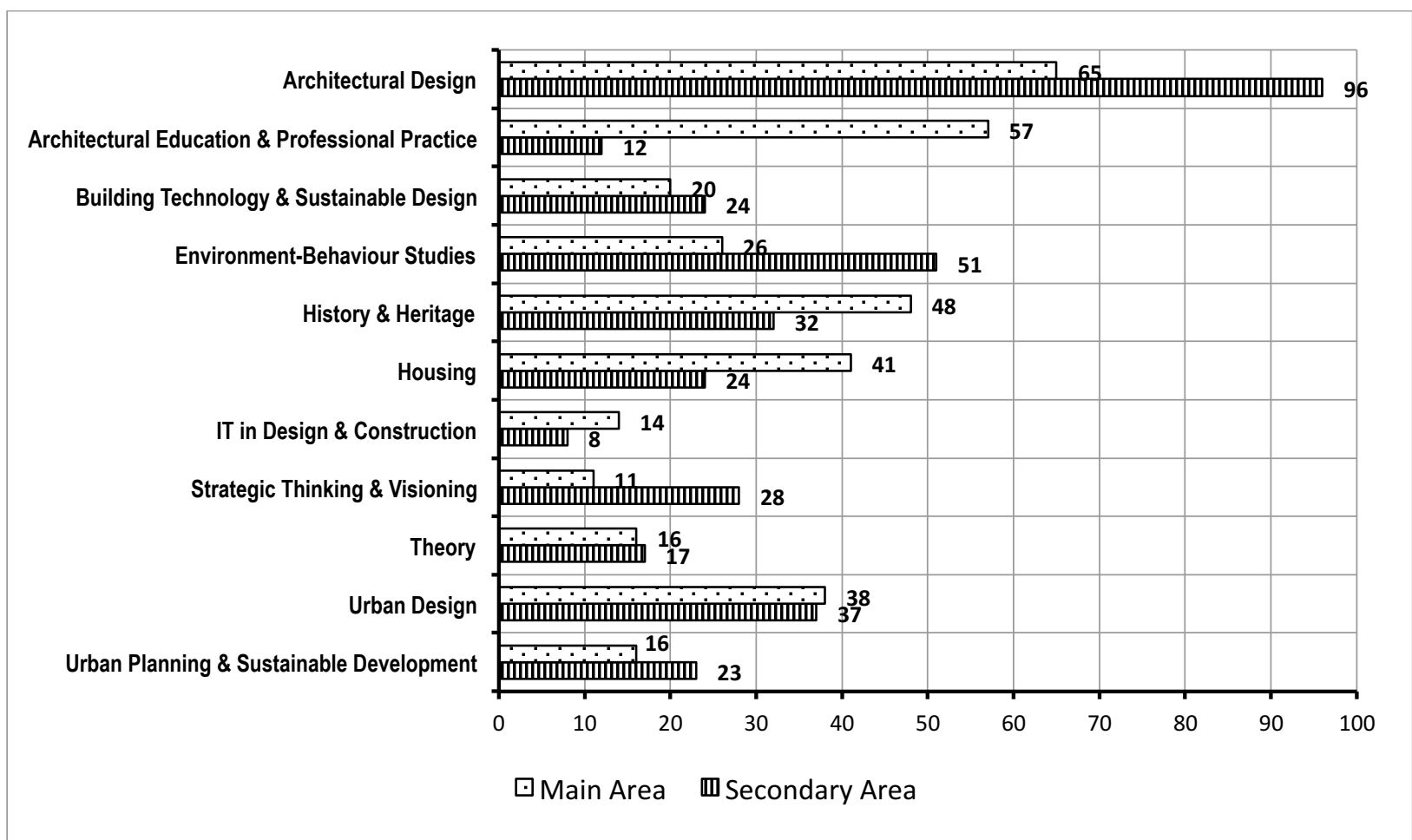

Figure 4: Frequency of research fields based on preliminary content analysis of the articles published in Archnet-IJAR 2007-2017 (Source: Authors).

\section{SIX SPECIAL THEMES - TIMELY AND PRESSING TOPICS}

At various intervals special issues were developed to address timely and pressing topics of interest to the international community. These ranged from traditional environments to design pedagogy and from post disaster reconstruction to heritage conservation, and to IT applications in design. Members of the advisory and editorial boards who are interested in developing collections relevant to their expertise typically carry out special issues as guest editors. While there were several special issues including those based on highest quality papers from relevant 
conferences such as those of IAPS-International Association People-Environment Studies and CAUMME-Conference of Architecture and Urbanism in the Mediterranean and the Middle East, six key special themes can be outlined as follows:

\author{
Vol 2, No 3 (2008) \\ Traditional Public Baths/Hammāms in the Mediterranean \\ Guest Editors: Magda Sibley and Fodil Fadli
}

Vol 4, No 2/3 (2010)

Design Education: Explorations and Prospects for a Better Built Environment

Guest Editors: Ashraf M. Salama and Michael J. Crosbie

Vol 7, No 3 (2013)

Post-Disaster Reconstruction

Guest Editors: Jason von Meding, Jamie Mackee and Thayaparan Gajendran

Vol 8, No 2 (2014)

Complexity, Patterns and Biophilia

Guest Editor: Nikos A. Salingaros

Vol 9, No 1 (2015)

The Contemporaneity of Built Heritage

Guest Editor: Remah Y. Gharib

Vol 9, No 3 (2015)

Design Creativity, Future Directions for Integrated Visualisation

Guest Editors: Jack Steven Goulding and Farzad Pour Rahimian

\title{
GLIMPSES FROM TWO RECENT THEME ISSUES
}

\section{Complexity, Patterns and Biophilia}

Based on our invitation to Nikos Salingaros, an international key figure in contemporary urban discourse, to lead a special issue on patterns and biophilia, he puts together a great piece that involves the works of biologists, urbanists, educators, historians, and philosophers (Salingaros, 2014). Inspired by the work of Christopher Alexander and under the theme of Complexity, Patterns and Biophilia, Salingaros describes the collection of articles as an alternative approach to shaping the built environment (Figure 5). In this issue, Ramray Bhat's contribution summarizes an innovative biological basis of form generation, and encapsulates results from Alexander's monumental book "The Nature of Order." His work synthesizes biology and design in a manner that offers learning about designing for a truly sustainable future (Bhat, 2015).

Michael Mehaffy offers a general blueprint for a sustainable city that cuts greenhouse emissions. Mehaffy juxtaposes philosophical underpinnings of the analysis of sustainability and the inadequacy of other similar blueprints (Mehaffy, 2014). Architectural education, on the other hand, is addressed in the article of Jan Michl asking the questions of why are architects not prepared with the material that integrates sustainability, biology, and learning from the natural world. His argument is based on the notion that architectural education has been focusing for a long time towards one particular design philosophy - the modernist, while ignoring problems that our world still encounters today (Michl, 2014). The work of Martin Horacek examines new museums but with a focus on the Acropolis Museum in Athens. In an objective analysis, he presents both pros and cons of the Museum while contrasting issues of national identity and global attraction (Horacek, 2014). 


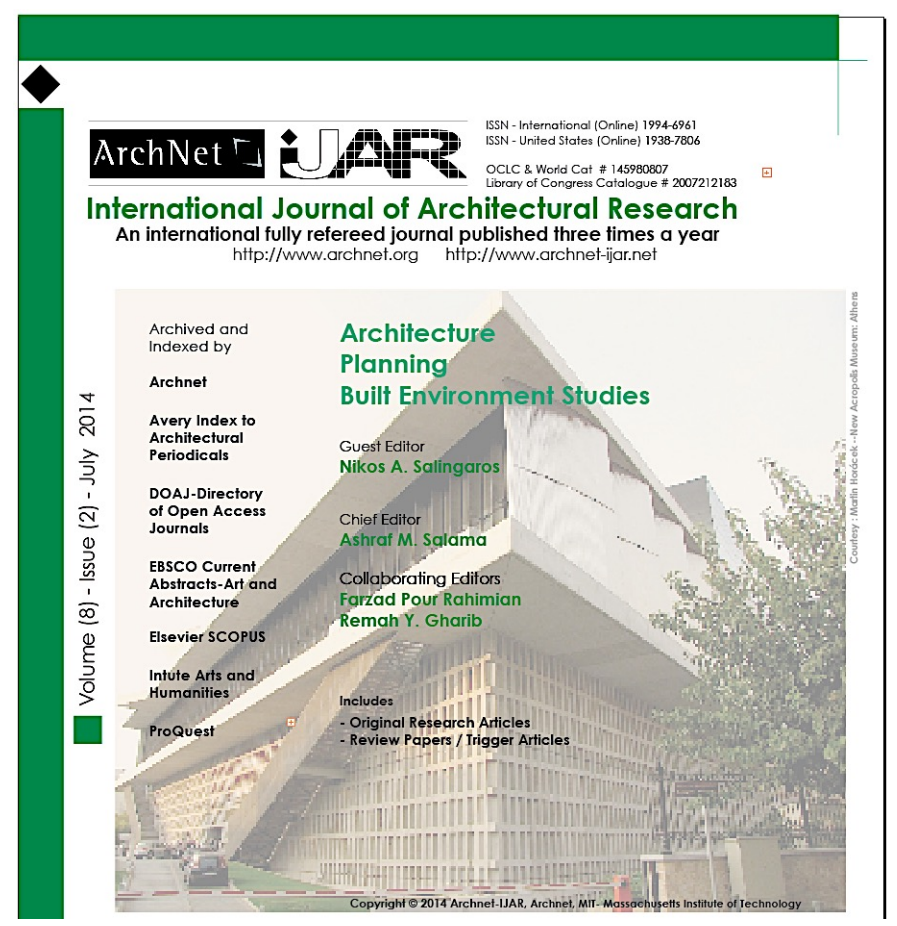

Figure 5: Cover of the special issue of ArchNet-IJAR (volume 8, issue 2 - July 2014) on Complexity, Patterns and Biophilia guest edited by Nikos Salingaros (Source; ArchNet-IJAR Archives).

According to Salingaros (2014), Catherine Ryan and her collaborators are practitioners in an innovative firm, offering a superior product that takes into account the biophilic effect. This takes advantage of the evolved human response to a natural environment, utilizing both direct and intimate contact with nature, as well as shapes, spaces, and surfaces that possess the same geometries found in living organisms (Ryan et al., 2014). The advantage of using Patterns from nature is that they provide a guide and checklist for any architect wishing to embed the documented health and psychological benefits in their own work.

Serge Salat and his collaborators study the city as a living organism and offer detailed and comprehensive comparison of three Western cities: Paris, New York, and Barcelona. Their study uncovers the morphological patterns while discredits the planning tools widely used since the end of World War II (Salat et al., 2014). James Kalb, a philosopher and jurist, offers an overview of Alexander's work, emphasizing its philosophical and inspirational aspects (Kalb, 2014). The issue concludes with an article from Jaap Dawson, an architect and educator offering a brief discussion on links that the professional community of architects and urban designers has lost over many decades (Dawson, 2014).

\section{Design Creativity - Future Directions for Integrated Visualisation}

Goulding and Pour Rahimian (2014) are the leaders and guest editors of a special issue under the theme of Design Creativity, Future Directions for Integrated Visualisation. Utilizing a multidisciplinary team approach they identify key issues in visualisation that involve bridging gaps and understanding overlaps in the AEC industry including: design-practice, design-production, designconstruction, and design-facilities management. The issue includes conceptual and theoretical frameworks, technological innovation and empirical research on designed products, and their tools and processes (Figure 6).

Building on their earlier work, Goulding and Pour Rahimian (2014) identify nine papers 
that represent world-leading scholars in the field with arguments and findings that present a new critical discourse on design visualisation and integration (Arif, Goulding and Rahimian, 2012; Goulding Rahimian and Wang, 2014). Soetanto et al. (2015) use questionnaire surveys, focus groups, observation of online meetings, and personal reflections to identify key success factors leading to the development of guidance for international collaborative design projects, via the implementation of collaborative design courses in the UK and Canadian universities over three academic years. Their work paves the road for educators to implement collaboration into courses.

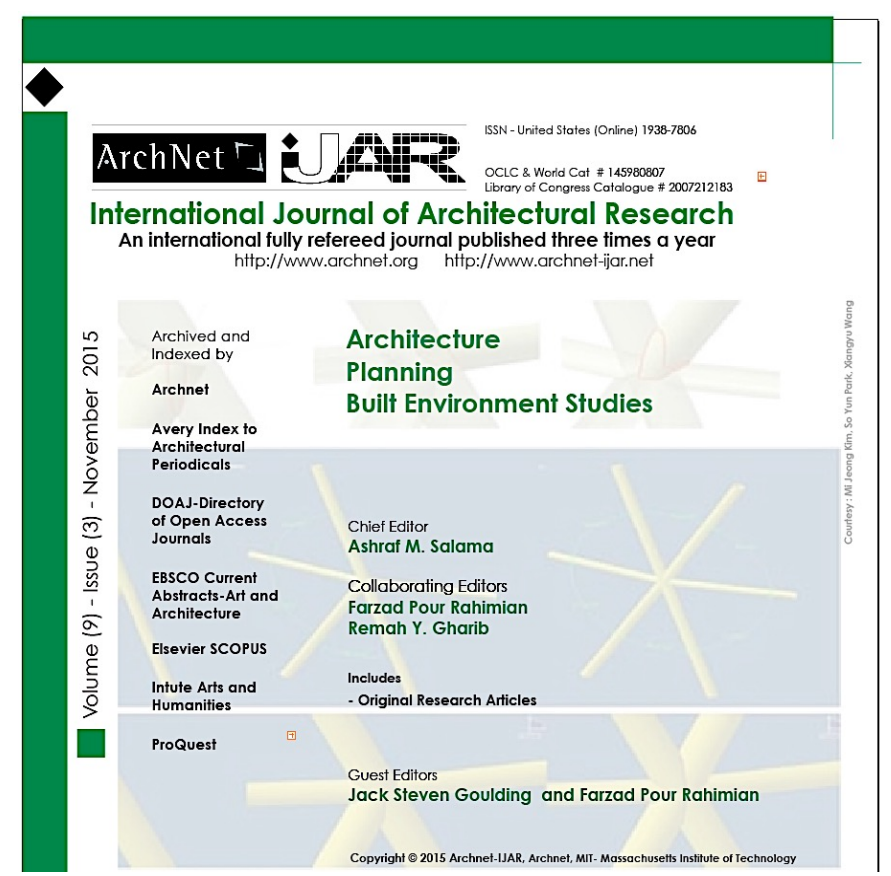

Figure 6: Cover of the special issue of ArchNet-IJAR (volume 9, issue 3 November 2015) on Design Creativity - Future Directions for Integrated Visualisation guest edited by Jack S Goulding and Farzad Pour Rahimian (Source; ArchNet-IJAR Archives).

Yuan et al. (2015) reflected on the challenges and risks associated with construction labour working on or near temporary structures. Introducing Cyber-Physical Systems (CPS) as a viable solution for preventing potential structural hazards, Yuan et al. (2014) provide a scaffolding system exemplar application scenario to demonstrate how CPS worked in structural monitoring, including the requirements and system architecture. Kim et al. (2015) emphasise the link between the effectiveness of visual displays and the quality of 'sense of presence' in immersive VR environments. Conducting an exploratory study on social interaction, with the remit of improving the presentation and communication of complex data through immersive simulation techniques their findings reveal the importance of embedding key concepts such as presence and immersion, as these were seen as pivotal factors that influenced communication (Kim et al., 2015).

The work of Maftei and Harty (2015) present findings from a study based on the design of a new hospital using immersive Virtual Reality (VR) technologies. They utilise the concept of reflective practice supported by video-based methods to analyse the ways design teams approach and employ collaborative design work using a full scale 3D immersive environment. Shih et al. (2015) introduce new insights on the impact of interfaces with design cognition. Employing protocol analysis methodology and coding video recordings of participants working on different projects, their findings reveal possibilities for designers to integrate different approaches 
into one design medium to facilitate design processes within AMM design environments. The work of Wang et al. (2015) focuses on learning styles, advocating that changes triggered by the digital paradigm shift affected perception, and that users' experience was not always favourable. Investigating the impact of VR technologies on the learning style preferences the study examines 245 architecture and construction students over a two-year period revealing that when virtual reality applications were used in teaching, learning behaviour favoured a more concrete 'experiential' mode of learning.

Park and Kim (2015) present a case for employing automatic methods for checking design quality and compliance with building codes (as opposed to conventional manual control methods), as this was considered particularly important with increased project complexity. The study also presents a BIM-based quality checking process case study demonstrating ways in which building health and safety issues can be resolved. Research findings suggest that BIMbased quality checking processes can be successfully employed to improve safety management.

Acknowledging the progressive increase in demand for use of BIM in historic buildings Megahed (2015) notes that BIM can present an accurate virtual model of a historic building in order to maintain the building through its entire lifecycle, including demolition. This approach, known as HBIM, represents a new paradigm within architectural heritage; the remit of which can be used for creating, conserving, documenting, and managing complete engineering drawings and information. Magahed highlights the different aspects of historic preservation and management through a smart open platform. Jamaludin et al. (2015) highlight the dynamics of daylighting within a residential college building and internal courtyard arrangement. Supported by various field measurements that complement computer simulations, findings convey that rooms can be augmented to consume less electricity usage, particularly for lighting purposes, to enhance the comfort of indoor living spaces.

\section{HIGHLIGHTS FROM RECENT DEVELOPMENTS AND CONTRIBUTIONS}

In this section we offer highlights from the latest volumes and issues which depict a complete picture of how ArchNet-IJAR is moving forward with rigor and quality contributions that cover a considerable number of issues while spanning across various geographies and cultures.

\section{ArchNet-IJAR in 2014}

Apart from the special issue on Complexity, Patterns, and Biophilia guest edited by Nikos Salingaros, there were two major issues following the typical pattern of publishing original research contributions. While issue 1 of volume 8 presents 11 contributions, in addition to a brief editorial, which came from scholars whose affiliations are spread across the globe, the issue 3 of the same volume offers a substantial body of work with 19 contributions addressing various issues within the fields identified (See Table 3 and Figure 4).

As part of volume 8 - issue 1, Al-Kodmany (2014) examines the appearance of landmark skyscrapers that stand on purely image-driven structures, where functionality and energy efficiency are taken in consideration. He views that green architectural aesthetics are a result of clean technology along with the practicality of substantial green design imperatives. Verderber (2014) explores qualitative and quantitative assessment of person-environment relations and the transactional relationship between human behaviour and the built environment. Following similar principles but in a different context and for a different building type, Rashid and Bartsch (2014) apply new theoretical frameworks to analyse Adelaide Mosque, as an influential building that has played a key role in the lives of Muslim settlers in Australia.

Both Al-Maimani et al. (2014) and Ujang (2014) study the traditional markets, but in two very different contexts. Al-Maimani et al. (2014) develop an experiential walkthrough framework for assessing three selected urban spaces within the traditional market (Souq) Mutrah, Muscat by examining their spatial and socio-cultural aspects while implementing direct systematic 
observation and behavioural mapping procedures. Ujang (2014) explores traditional shopping districts in the city centre of Kuala Lumpur, Malaysia, where personal interviews and field observations were conducted in order to interpret the meanings attached to the users' experience of the traditional shopping streets located in the area. Notably, the work Al-Maimani et al. (2014) is presented based on other studies conducted in other contexts to uncover experiential dimensions of urban open spaces (Salama, Khalfani, and Al-Maimani, 2013; Salama and Azzali, 2015). Along the same line of examining the relationship between the built environment and users, Tezgelen and Karaman (2014) define user's comfort within houses in four residential areas in Izmir. In order to interrogate users' satisfaction, she applies six parameters that include thermal comfort, visual comfort, acoustic comfort, humidity and moisture control and design quality. Essawy et al. (2014), one the other hand, conduct several experiments on selected case studies to measure the effect of buildings on the brain waves of building users by applying Brain Wave Frequency Charts through EEG device for assessing architectural quality.

Megahed (2014) addresses the historical architectural styles of Port Said, Egypt, that attract people's interest while preserving the valuable built heritage which in return confront the challenges of sustainable development. In a related paradigm, Gharib (2014) explores the concept of sustainable management framework based on the relationship between factors of 'importance' and 'performance' in order to study the historic centres of Bath and Cambridge cities. Addressing the autistic user, Mostafa (2014) emphasises the development and use of a Sensory Design Theory and its seven principles as catalysts for design guidelines while generating various criteria not typically used in educational environments and learning spaces. On the other hand, Zagora and Samic (2014) investigate the implications of political and social transition on the contemporary architectural production in Sarajevo with respect to three representational typologies that are based on Henri Lefebvre's theory of "Production of Space."

The 19 contributions published in volume 8 - issue 2 highlight key issues relevant to the education and practice of architecture and urbanism. Cranz et al. (2014) present a research based design project centred on semantic ethnography as part of the NAAB-accredited programme at the University of California Berkeley. Her work highlights the benefits of research led pedagogy that extends beyond the academy. Following a similar approach but with a focus on design-build experiences, Gaber (2014) explores the opportunity for a commitment to new pedagogy that would address changes and needs of the profession of architecture in the Canadian context and within the unique particularities of a new school of architecture at Laurentian University. Maturana (2014) assesses the design studio experience, in the Australian context, as a problem-based and case-based learning paradigm while Elshater (2014) discusses the way in which educational institutions in Egypt follow the trends adopted in post-war European cities but continually ignoring the decline of Egyptian cities. She proposes a new urban design module for integration within curricula offered by schools of architecture. Her work advocates solving the problems of the Egyptian city within identified learning parameters and outcomes.

Al-Lahham (2014) argues that most of the Islamic cities expose heterogeneity in the current structures of built environment due to the contradiction, which stems from the amalgamation of traditional Islamic principles and contemporary aspects of built environment. Salama (2014) contextualises the city of Doha within the regional cultural politics, with the aim of demonstrating the impact of potential and actual regional forces on image making practices. Meagher (2014) investigates the reason that responsive components of architecture have seldom been granted an aesthetic purpose. His work suggests alternative ways of thinking about the elements of buildings that change over time in response to the environment. In addition, Asfour (2014) explores the notion introduced by Vitruvius that emphasises that the spatial experience of a building instils positive feelings in its users and reflects a reciprocal relationship. He discusses the Vitruvius's idea by referring to the perceptions of British and Egyptian museums as timeless pieces that go beyond cultural restrictions. A typological study was undertaken by Erdogan and 
Erkış (2014) reflects the unique values of the traditional settlement organisation of the city of Sille, Turkey.

Gur (2014) investigates selected "child development centres" (CDCs), located in Turkey which offer preschool education, from the perspective of the relationship between the physical quality and the development of personality, emotions, cognitive and social abilities of a child. On the other hand, Martin (2014) implements an exploratory survey of non-healthcare practitioners to identify current understanding of Evidence-based design (EBD), degree of implementation of EBD, and interest in learning more about EBD.

Two studies implement field surveys based on observation and questionnaires directed to city centre users, the first by Peschardt and Stigsdotter (2014) who demonstrates how health is promoted by the potential of pocket parks in the dense city area of Copenhagen by analysing Dantes Plads as a pocket park, before and after a redevelopment initiative. The second by Asfour and Ghali (2014) who argue for the need for urban development strategies in the context of the city centre of Rafah, Palestinian Territories, with the aim of including transportation, environmental quality, shopping activities, investment opportunities, and visual perception as important parameters that guide the development of strategies.

Ernawati and Moore (2014) investigate similarities and differences in impressions between three groups: international tourists, domestic tourists and residents in an international heritage tourism site, in the context of Kampong Taman Sari, Indonesia, in order to their impression and comprehension of 'attractiveness.' Farahani and Lozanovska (2014) apply a conceptual framework that pertain to social cohesion which exhibits that the sense of community can be generated within the residential environment while the social life is supported by the commercial environment in the same neighbourhood.

Smith (2014) applies comparative analysis of pre-modern urban housing forms including individual houses; group houses; contiguous houses; houses within walled compounds; and apartment buildings, which are primarily influenced by causal forces that include cultural tradition, density, and political dynamics. In a different context, Al-Thahab et al. (2014) investigate privacy and everyday life as determinants of the physical properties of the built and urban fabric in Iraqi houses and local neighbourhoods (Mahalla) along with their impact on traditional Islamic settlements and architecture of the home environment in the contemporary city. Nia et al. (2014) study how the vernacular roofs in Kashan, Iran have responded to people's behaviours by improving physical and mental health and offering spiritual and a spectrum of intangible benefits. Othman et al. (2014) examine how the design of Muslim homes in Brisbane, Australia could achieve optimal privacy and extend hospitality to guests inside and outside their homes simultaneously.

\section{ArchNet-IJAR in 2015}

In addition to the two special issues published in 2015 on The Contemporaneity of Built Heritage, guest edited by Remah Y. Gharib, and on Design Creativity, Future Directions for Integrated Visualisation, guest edited by Jack Steven Goulding and Farzad Pour Rahimian, ArchNet-IJAR in 2015 witnessed the development of a key issue (volume 9, issue 2 - July 2015) that clearly demonstrates the rigor of the journal's review process while reflecting the multifaceted nature of architecture, planning, and built environment research (Figure 7). The issue involves a wide spectrum of views related to housing research. Five papers juxtapose these views in various contexts.

Agatangelo Soler Montellano addresses the notion of indeterminacy as one of the rising trends in flexible housing design. Based on a series of users interviews, photographs, diagrams and new drawings that show how people spatially and socially use their apartments Montellano assesses the validity of indeterminacy as an architectural response to social change in the context of Spain (Montellano, 2015). Relating to social and demographic transformations and 
spatial challenges Sebastiaan Gerards, Roel De Ridder, Sylvain De Bleeckere present their findings of exploring multi-generational dwelling in the context of Flemish communities in Belgium. Utilizing a 'research by design' approach to explore and at the same time encounter design issues the authors experiment with this new housing concept in a specific, but realistic setting through a workshop format. The exploration results in establishing key considerations for further research, toward an effective implementation of multi-generational dwelling in Flanders (Gerards, De Ridder, De Bleeckere, 2015).

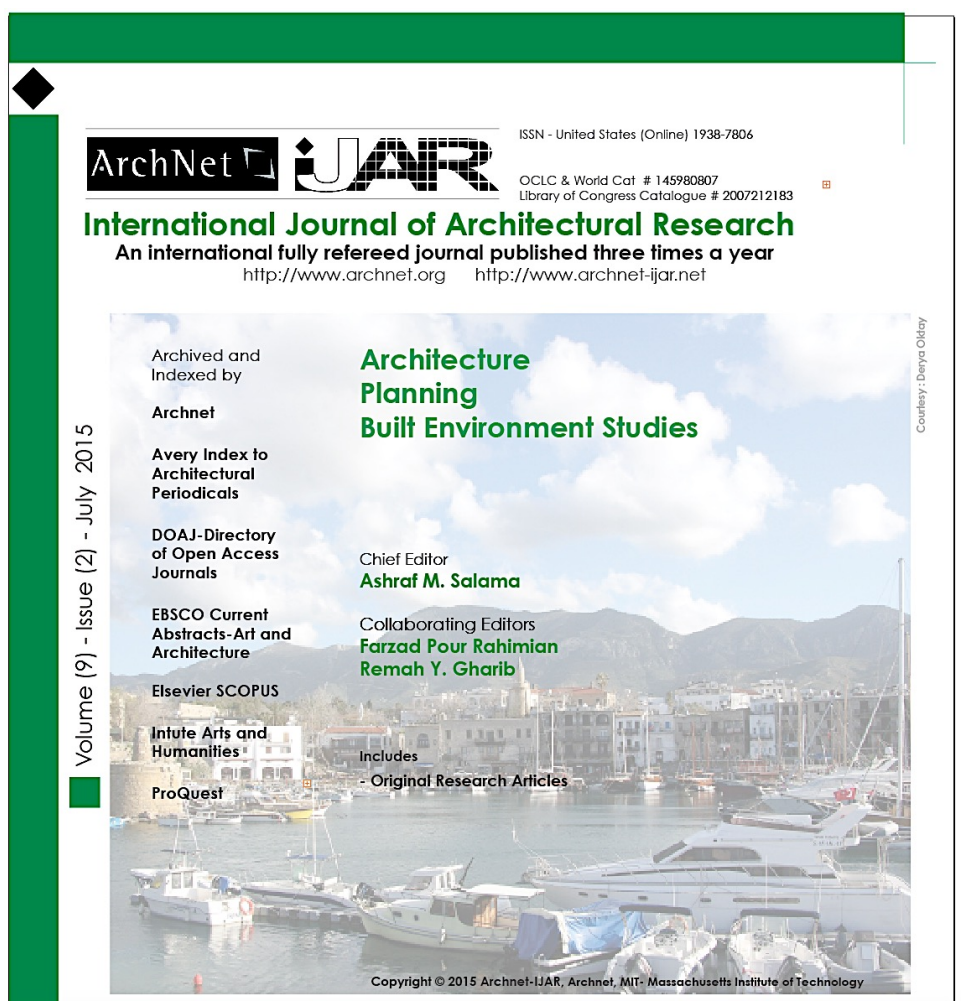

Figure 7: Cover of ArchNet-IJAR (volume 9, issue 2 - July 2015), edited by Ashraf M. Salama, which includes 16 contributions reflecting the multifaceted nature of architectural research and built environment studies

(Source; ArchNet-IJAR Archives).

The work of Mohd Firrdhaus Mohd Sahabuddin and Cristina Gonzalez-Longo takes a different route and places emphasis on thermal comfort in the context of Malaysian social housing. Their work introduces a new typology that aims at enhancing thermal comfort and argues that traditional values should be integrated into social housing design to achieve a certain measurement of natural ventilation in a typical Malaysian residential unit or a house (Sahabuddin and Gonzalez-Longo, 2015).

Raffaello Furlan argues for the need to reestablish the relationship between cultural traditions and house form. Furlan addresses the nature of vernacular architecture in a precise context by placing emphasis on the architectural form of vernacular houses built in Brisbane, Australia in the post WWII period by first generation Italian migrants. His exploration involves various aspects including the spatial organization, materials and construction techniques, decorative elements on the façades, and ways in which these were materialized through migrants' cultural traditions (Furlan, 2015). The study of Seyed Reza Hosseini Raviz, Ali Nik Eteghad, Ezequiel Uson Guardiola, and Antonio Armesto Aira aims to establish guidelines for future flexible housing design. It involves two case studies relevant to Dutch housing with a focus 
on the spatial organization and its potential in achieving efficient spatial configuration (Raviz, Eteghad, Guardiola, and Aira, 2015).

In dealing with the relationship between people and their surroundings and the creation of sustainable environments Marta Brković, Oriol Pons, and Rosie Parnell offer a participatory postoccupancy approach within which their study was undertaken in the context of Barcelona, Spain. In essence, their work juxtaposes schools and schooling and argues that new models for exploring the pedagogical potential of sustainable schools should be developed and the efforts of all relevant parties should be synchronized; from architects to governments, and from students to teachers.

The work of Sharifah Khuzzan, Jack Steven Goulding, and Farzad Pour Rahimian hypothesizes that learners can learn better with a bespoke personalized learning environment, in which the deployment of teaching and learning material is directly augmented towards their individual needs. They present findings from the development of a holistic conceptual Diagnostic Learning Styles Questionnaire (DLSQ) Framework, which is comprised of six interrelated dependencies (i.e. Business Strategy, Pedagogy, Process, Resources, Systems Development, and Evaluation). The convergence of these dependencies directly influences pedagogical effectiveness. Validating their argument they maintain that such a framework can enable better augmentation of organizations and educational institutions of their strategic priorities and learnerspecific qualities (Khuzzan, Goulding, and Pour Rahimian, 2015).

In the context of rapidly growing Middle Eastern cities, Ashraf Salama and Anna Grichting offer an overview of landscape interventions in three Middle Eastern cities (Cairo, Doha, Riyadh) and identify three levels of contribution of contemporary landscapes that correspond to three landscape typologies: the edge, the center, and the backbone. They examine a number of issues underlying each landscape typology and offer an interpretation on the contribution of each typology to its context and to the city within which it exists (Salama and Grichting, 2015). On the other hand, placing their work within the notion of 'architecture and realism' Renatro Capozzi, Adelina Picone, and Federica Visconti offer a philosophical interpretation that contrasts realism with the post modern condition in the context of a city and present a series of key projects and pedagoicla design exercises that manifest such a juxtaposition (Capozzi, Picone, \& Visconti, 2015).

Expanding the scope of her earlier writings on traditionalism, authentication and fabrication of the built environment of Muslims, which was published earlier in IJAR (AI-Lahham, 2014) Abeer Al-Lahham critically examines the concept of the neighborhood in light of the 'New Urbanism' discourse and the capacity of these to achieve their promises in creating coherent structure for contemporary societies. Her examination reveals that these were merely housing schemes and manifest failures in achieving what they claimed to (Al-Lahham, 2015). In London; a totally different context, Saul M. Golden, lan Montgomery and Taina M. Rikala develop an argument that call for architects to act more explicitly to promote greater openness and usevalue, rather than more objectified and controlled exchange-value approaches to the public domain in private-led development interventions. By comparing a number of parameters in two cases the individual practitioner's experiences of architecture practice with explicit intentions to influence better quality shared city space, and examining professional norms relevant to commercial clients and wider society, they conclude that employing a wide range of strategies can contribute to better engagement of people in contemporary urban societies (Golden, Montgomery, Rikala, 2015).

Two papers are developed in the context of the Mediterranean. Pantoleon Skayannis, Angelos Kyratzakos offer a chronological development of planning in Thessaloniki, Greece since the mid-eighties. Specifically, they discuss the Lachanokipoi area of the 'Western Entrance' of the city and highlight three periods of development with a focus on economic drivers and trajectories. 
Their work concludes with a call for urban renewal of the area as an integral part of the general spatial plans adopted by city authorities (Skayannis and Kyratzakos, 2015).

Another research intervention in the Mediterranean region is articulated in the work of Derya Oktay, Havva Alkan Bala. By utilizing an attitude survey they offer a holistic research approach to measuring urban identity in the context of Kyrenia, Northern Cyprus. Their findings indicate that although historic landmarks are so powerful in constructing the urban identity, traditional urban pattern and social life have not been found significant in constructing the images of the city unless local residents frequent them. Among other findings their survey reveals that the new housing developments that lack locally appropriate architectural and contextual qualities do not necessarily influence the urban image of the area (Oktay and Bala, 2015).

Shehada, Ahmad, Yaacob and Keumala also emphasize issues related to conservation of heritage buildings in a paper. They argue that Sustainable building conservation can be accelerated by an appropriate reuse selection and evaluation criteria and procedures. They develop an inclusive methodology in order to optimize adaptive reuse selection of heritage buildings. Utilizing a Delphi Method (DM) with fuzzy logic theory, they apply their methodology on Khan Al-Wakalah as a case from Palestine. Findings demonstrate that there is a clear evidence of a link between the criteria and the key substantial factors and that such a link is of great importance and should be further considered in the evaluation and selection processes (Shehada, Ahmad, Yaacob and Keumala, 2015).

Shatha Malhis, Fatima Al-Nammari utilize the space syntax methodology in addition to interviews and ethnographic analyses to examine the three-floor gallery plans of the Abu-Jaber Museum that correspond to the two stages in the evolution of the Abu-Jaber House: 1880, when it was originally constructed to house the families of three affluent brothers; and 2007, when it was rehabilitated into a local heritage museum. In essence their work establishes the three-way interaction between spatial structures and architectural language, interpretations of conservation priorities and curatorial principles (Malhis and Al-Nammari, 2015). Nelly S. Ramzy on the other hand builds her work on Biomimicry as a growing area of interest in architecture. She demonstrates that adopting biophilia and biophilic design principles leads to enhanced outcomes in terms of sustainability as well as human psychology and users well being (Ramzy, 2015).

The sixteen contributions presented in this edition of IJAR offer a wide variety of ideas, concepts, arguments, and research findings presented by authorities, distinguished academics, and committed scholars. They provide a great venue for achieving excellence in research in architecture and urbanism while paving clear pathways for debating the complexity of built environment.

\section{ArchNet-IJAR in 2016}

In 2016, ArchNet-IJAR has not introduced special or theme issues to the architectural community. However, a total of 45 articles have been published following the pattern of publishing - three times per year in March, July, and November (Figure 8).

The edition of IJAR volume 10, issue 1, March 2016 includes articles that are based on theoretical positions and empirical research findings with debates centred on three main areas 1) Design Thinking, Processes, and Evaluation (papers 1-6); 2) Design and Construction Analysis (papers 7-11); and 3) Urban and Contextual Studies (papers 12-21). (See: http://www.archnetijar.net/index.php/IJAR/issue/archive). Contributions come from all corners of the world including Australia; Belgium; Brazil; Colombia; Egypt; Germany; Indonesia; Iran; Italy; Libya; Malaysia; Qatar; South Africa; Turkey; United Kingdom; United States. These articles contribute to advancing the discourse on architecture and urbanism while paving the road for future studies in the field. Key articles include the work of Amy Huber, Karen Kim and Edward Steinfeld, and Salama, Wiedmann, Thierstein, and Al Ghatam. 

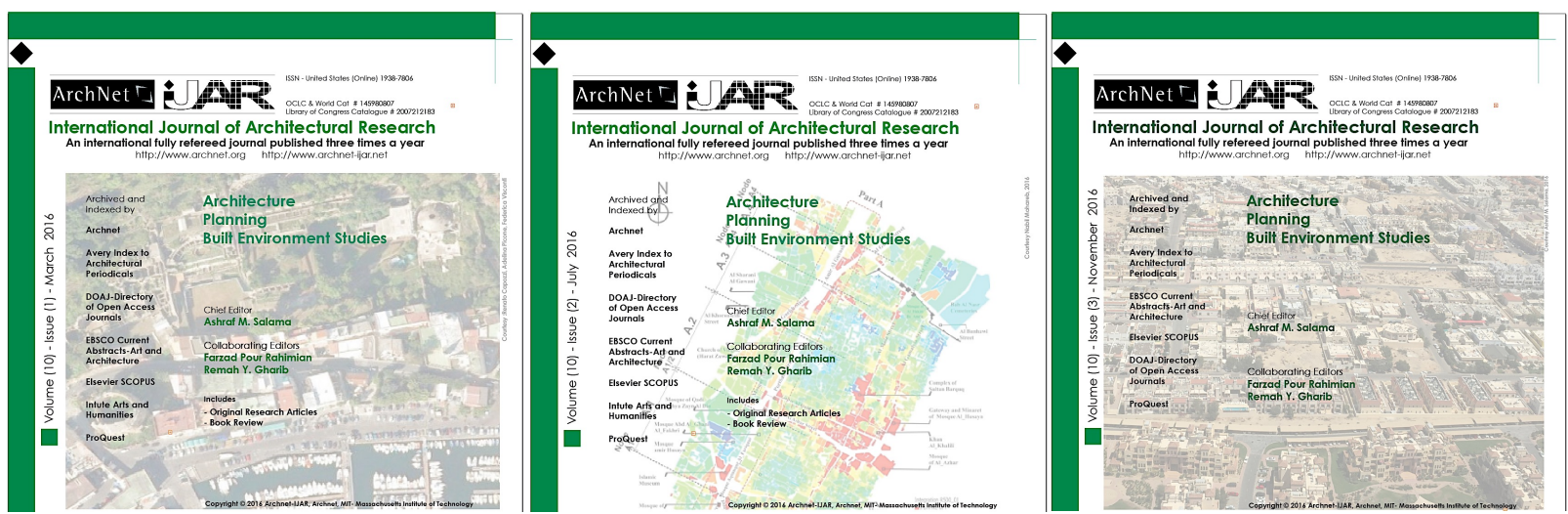

Figure 8: Covers of ArchNet-IJAR (volume 10, issue1, 2, 3) (Source; ArchNet-IJAR Archives).

Huber (2016) demonstrates how interior design practitioners utilise research, the outcome of which become sources of information that enable effective communication of research findings as well as design ideas. On the other hand, Kim and Steinfeld (2016) analyse stairway designs published in Architectural Record between 2000 and 2012. Images of stairways were classified as either hazard-free or hazard(s)-present using a hazard identification checklist, and the frequency of visible design hazards was tabulated. Their study reveals interesting findings where a total of 578 stairways were scanned in articles and advertisements, of which $78(13.5 \%)$ were product advertisements. Sixty-one per cent of the stairways had at least one visible design hazard including nearly half $(47 \%)$ in product advertisements. They conclude that the need for improved professional education and media attention to safe stairway design.

On a very different scale, Salama et al., (2016) present a comprehensive coverage of a research project of the National Priority Research Program of Qatar National Research Fund, entitled 'Investigating the Qualities of the Urban Environment in Emerging Regional Metropolises', which was carried out between 2011 and 2014 through the joint collaboration of Qatar University and Technische Universität München. Premised on the assumption that non-physical economic aspects and the qualities of the urban environment are interdependent, they present multi-layered comprehensive methodology that reveals key contextual particularities in the context of Doha with recommendations aimed at potential beneficiaries including public sector organizations, private sector and real estate development companies, and academia.

The volume 10 - issue 2, July 2016 includes debates on a wide spectrum of issues, explorations and investigations in various settings. Contributions in this issue come from scholars from well-established institutions in Australia, Canada, Egypt, Italy, Jordan, Lebanon, Malaysia, United Kingdom, and United States. They address issues related to urban displacement with respect to low income communities; vernacular traditional building types in north America; accessible housing and health related quality of life; sustainable tall buildings in the Middle East and South East Asia; urban patterns in historic Cairo; the architecture of the Umayyad; landscape elements and their contribution to walkability; natural ventilation in terrace housing; abandoned housing projects in Malaysia; assessment of a courtyard housing project in Beijing; movement and interaction in the workplace; neighbourhood regeneration; and the role of sketching in the visual transformation of architectural design.

Key articles can be highlighted here: Carnemolla and Bridge (2016) qualitatively measure the impact of home modifications on health-related quality of life by applying a mixed-method exploratory study which emphasises the potential of the spatial environment to improve community health and wellbeing. Zhang (2016) uses qualitative and quantitative data to analyse 
the Juer Hutong new courtyard-housing prototype located in Beijing, China. Her study reveals lessons and design models of courtyard garden houses for future design practice.

At an urban scale Mohareb (2016) quantitatively assesses the micro and macro urban edges of Historic Cairo with reference to their spatial configuration. The study reveals that there are obvious patterns that impact the spatial configurations and related activities along the urban edges, forming different type of barriers but poor living conditions while affecting the spatial integration, architectural features, and the surrounding land uses. Verderber (2016) examines everyday places and iconic building types including suburbia roadside motels, vintage diners, fast food franchises, residential trailer parks, signage, unique commercial establishments, and shopping malls. These places and buildings are generally classified as expressions of folk vernacular culture. Visual documentation, interviews, and archival fieldwork provided the basis for the articulation of relevant typologies.

11 articles were published in ArchNet-IJAR edition of November 2016. They introduce significant issues relevant to creative thinking in design, cultural expression in university campus design in Nigeria, action planning for heritage tourism in Jordan, among other important issues. Choi and Kim (2016) explore the potential of reasoning methods, specifically analogical reasoning and metaphorical reasoning, in design education towards encouraging students to adopt creative thinking in the design studio process. This research provides a basis for future empirical studies to examine creativity within design pedagogy, despite the fact that there are several limitations to assess students' creativity and interpret their design actions and choices.

Two analytical articles emphasise that traditional architecture should be seen as a source for developing new architectural designs and urban design proposals within the contemporary Islamic city. García-Templado and Gharib (2016) develop a knowledge-based descriptive framework as a tool that serves to enrich the architectural descriptions of historic buildings built in the Iberian Peninsula during the Islamic rule in Al-Andalus. Their study utilises both qualitative and quantitative details, abstract characteristics, as-built drawings, and spatial patterns. Furlan and Petruccioli (2016) demonstrate that the old urban fabric in the city of Doha is a source of generative ideas and design principles, which should be embedded into future design proposals.

\section{CONCLUSIONS, FUTURE INITIATIVES AND ASPIRATIONS OF ARCHNET-IJAR}

From a very modest beginning ArchNet-IJAR has developed into one of the well established and leading journals within the disciplines of architecture and urban studies. While the journal continues to receive massive numbers of papers, it also continues to conduct its review process diligently and rigorously. The quality of papers published in the journal including those called for and included in special theme issues should be noted. The position that ArcNet-IJAR has achieved as a Q2 journal within SCImago Journal Ranking and CiteScore Ranking of Scopus are manifestation of this quality in the last three years. However, this requires a sustained quest for quality, rigor, and diversity of topics, enhanced citations, and international collaboration.

The focus of ArchNet-IJAR continues to be centred on research studies, criticisms and critical analyses about the creation, use, and evaluation of different types of environments at the macro and micro scales. This includes original empirical research papers, analytical case studies, and high quality position papers that contribute to the advancement of knowledge in architecture and urbanism. The journal will continue to balance its content to cover both global south and global north. Primarily, the areas underlying the main focus of the journal will continue to include:

- Architectural Design Theories, Processes, Methods and Practices

- Architectural Education: Pedagogy and Design Studio Teaching Practices

- Housing Design and Neighbourhood Planning

- Human Environment Interaction (Environment-Behaviour Studies) as it applies to buildings, urban spaces, and cities, etc.

- IT Applications in Creative and Construction Industries 
- Post Disaster Design and Development Processes

- Sustainable Design, Planning, and Urban Conservation

- Urban History and Development of Cities

- User Centred Assessment studies (Post Occupancy Evaluation)

While current challenges mandate alternative approaches to online publishing, ArchNet-IJAR will continue to work on various aspects of improvement, but most important is being part a larger publishing house is one of the priorities. It is envisaged that key improvements would include:

- a more efficient workflow;

- offloading non academic/non-technical activities from the editors including language editing, reference formatting, and general reviews,

- graphics, lay outing, and production,

- enhanced visibility and publicity, and e) enhanced documentation, Metrics, and Altmetrics.

ArchNet-IJAR is currently planning to include selected quality papers from the following high profile international academic gatherings:

- AJIC 2016 -- 5th Architectural Jordanian International Conference, which was recently organized by the Jordanian Society of Engineers (December 2016)

- Sustaining Heritage in the Digital Age - Towards Virtual Environments for Middle East's Cultural Heritage (February 2017)

- PLEA (Passive and Low Energy Architecture) -- PLEA 2017 Conference in Edinburgh, UK (3-5 July 2017) --"Education and Training" Forum which is chaired by the Chief Editor

- CAUMME (Contemporary Architecture and Urbanism of the Mediterranean and the Middle East) CAUMME 2018 Conference in Istanbul, Turkey (22-23 Nov 2018) for which the Chief Editor is a member of its Advisory Board

In the current issue (volume 11 - issue 1) in which this article is included, 9 contributions are selected to open our new round of discourse and research. Chitrakar, Baker, and Guaralda (2017) discuss emerging challenges in the management of public spaces in urban neighbourhoods in Kathmandu, Nepal. On the same topic but in a commercial setting in SouthWest Nigeria Agboola, Rasidi and Said (2017) analyse the influence of open space utilisation on residents' attachment taking the case of rural market square. Utilising a case study of LEEDcertified low-income multifamily housing Behbehani and Prokopy (2017) explores the appropriation of built heritage and pro-environmental behaviours.

Two articles place emphasis on exploring traditions and the vernacular. Diasana Putra, Lozanovska and Fuller (2017) develop and validate a methodology to assess the transformation of traditional houses in Bali. Yet, Jaiyeoba, Asojo, and Amole (2017) examine the Yoruba vernacular as a paradigm for low income housing addressing the context of Ogbere, Ibadan, Nigeria. In a very different context, Faggion and Furlan (2017) interrogate the embedded cultural meanings of the houses of Italian migrants in Brisbane, Australia.

Lesley J. McIntyre and lan Ruaraidh Harrison (2017) base their work on the imperative that the built environment influences the wellbeing of older people in care homes. Their work presents an analysis of the outcomes of ethnographic observations of five urban care homes in the UK. Developing the case that designing for enablement, physical activity, and social connectivity, their findings offer lessons relevant to five significant qualities of the built environment: Spatial Legibility, Spatial Interconnectedness, Spatial Traversability, Spatial Diversity, and Spatial Aesthetics.

Aiming to create a composite social sustainability index for India that contributes to a better understanding of the dynamics of social sustainable development Sudha, Chakraborty, and Misra (2017) investigate the four facets of urban sustainability: social, economic, environmental and institutional, in an integrated manner while testing the composite index in the context of Odisha, in Eastern India. The outcome of this examination reveals that education is fundamental 
to improving the social sustainability and that urban policies should focus on the critical zones of education, health and access to basic services. Last but not least Khan and Loke (2017) provide a framework within which augmented reality can be examined in the context of the participatory spatial design context.

\section{REFERENCES}

Agboola, O. P., Rasidi, M. H., and Said, I. (2017). The Influences of Open Space Utilization on Residents' Attachment with Community: A Case Study of Rural Market Square in South West Nigeria. ArchNetIJAR: International Journal of Architectural Research,11(1), 44-66.

Al-Kodmany, K. (2014). Green Towers and Iconic Design: Cases from Three Continents. ArchNet-IJAR: International Journal of Architectural Research, 8(1), 11-28.

Al-Lahham, A. (2014). Traditionalism or Traditiona-Lieism: Authentication or Fabrication? ArchNet-IJAR: International Journal of Architectural Research, 8(3), 64-73.

Al-Lahham, A. (2015). Rethinking the concept of the neighborhood: An Enabling or a Housing Model?. ArchNet-IJAR: International Journal of Architectural Research, 9(2), 152-169.

Al-Maimani, A., Salama, A. M. and Fadli, F. (2014). Exploring Socio-spatial Aspects of Traditional Souqs: The Case of Souq Mutrah, Oman. ArchNet-IJAR: International Journal of Architectural Research, $8(1), 50-65$.

Al-Thahab, A., Mushatat, S., \& Abdelmonem, M. (2014). Between Tradition and Modernity: Determining Spatial Systems of Privacy in the Domestic Architecture of Contemporary Iraq. ArchNet-IJAR: International Journal of Architectural Research, 8(3), 238-250.

Arif, M., Goulding, J., \& Pour Rahimian, F. (2012). Promoting off-site construction: Future challenges and opportunities. ASCE Journal of Architectural Engineering, 18(2), 75-78.

Asfour, K. (2014). Vitruvian Character: The Case of the Egyptian Museum. ArchNet-IJAR: International Journal of Architectural Research, 8(3), 105-116.

Asfour, O., \& Abu Ghali, S. (2014). Urban Development Strategies of City Centres: The Case of Rafah City, Palestinian Territories. ArchNet-IJAR: International Journal of Architectural Research, 8(3), 195-206.

Behbehani, L. J. and Prokopy, L. S. (2017). The Appropriation of Built Heritage and Pro-Environmental Behaviours: A Case Study of LEED-Certified Low-Income Multifamily Housing. ArchNet-IJAR: International Journal of Architectural Research,11(1), 67-82.

Bhat, R. (2014). Understanding Complexity through Pattern Languages in Biological and Man-Made Architectures. ArchNet-IJAR: International Journal of Architectural Research, 8(2), 8-19

Brković, M., Pons, O., \& Rosie Parnell, R. (2015). Where sustainable school meets the 'Third Teacher': Primary school case study from Barcelona, Spain. ArchNet-IJAR: International Journal of Architectural Research, 9(2), 77-97.

Capozzi, R., Picone, A., \& Visconti, F. (2015). The city built in elementary parts: An alternative to Delirium of post-metropolis. ArchNet-IJAR: International Journal of Architectural Research, 9(2), 137-151.

Carnemolla, P., \& Bridge, C. (2016). Accessible Housing and Health-Related Quality of Life: Measurements of Wellbeing Outcome Following Home Modifications. ArchNet-IJAR: International Journal of Architectural Research,10(2), 38-51.

Chitrakar, R. M., Baker, D. C., and Guaralda, M. (2017). Emerging Challenges in the Management of Contemporary Public Spaces in Urban Neighbourhoods. ArchNet-IJAR: International Journal of Architectural Research,11(1), 29-43.

Choi, H., \& Kim, M. (2016). The Potential of Reasoning Methods as a Teaching Strategy Supporting Students' Creative Thinking in Architectural Design. ArchNet-IJAR: International Journal of Architectural Research, 10(3), 6-20.

Cranz, G., Lindsay, G., Morhayim, L., \& Sagan, H. (2014). Teaching Semantic Ethnography to Architecture Students. ArchNet-IJAR: International Journal of Architectural Research, 8(3), 6-20.

Davis, A. and Preiser, W. F. E. (2012). Architectural Criticism in Practice: From Affective to Effective Experience. ArchNet-IJAR: International Journal of Architectural Research, 6(2), 24-42.

Dawson, J. (2014). A Full House. ArchNet-IJAR: International Journal of Architectural Research, 8(2), 99106.

Diasana Putra, I D.G.A., Lozanovska, M. and Fuller, R. J. (2017). A Methodology to Evaluate the Transformation of Traditional Balinese Houses as a Consequence of Tourism. ArchNet-IJAR: International Journal of Architectural Research,11(1), 83-100. 
Elshater, A. (2014). Prosperity of Thought versus Retreat of Application: A Comprehensive Approach in Urban Design Teaching. ArchNet-IJAR: International Journal of Architectural Research, 8(3), 45-63.

Erdogan, E., \& Boztepe ERKIS, Ş. (2014). Sille Settlement in the Context of Sustainable Historical Fabric and Façade Analysis of Its Traditional Houses. ArchNet-IJAR: International Journal of Architectural Research, 8(3), 117-135.

Ernawati, J., \& Moore, G. (2014). Tourists' and Residents' Impressions of a Heritage Tourism Site: The Case of Kampong Taman Sari, Indonesia. ArchNet-IJAR: International Journal of Architectural Research, 8(3), 181-194.

Faggion, L. and Furlan, R. (2017). Cultural Meanings Embedded in the Façade of Italian Migrants' Houses in Brisbane, Australia. ArchNet-IJAR: International Journal of Architectural Research,11(1), 119-137.

Farahani, L., \& Lozanovska, M. (2014). A Framework for Exploring the Sense of Community and Social Life in Residential Environments. ArchNet-IJAR: International Journal of Architectural Research, 8(3), 223-237.

Furlan, R. (2015). Cultural traditions and architectural form of Italian transnational houses in Australia. ArchNet-IJAR: International Journal of Architectural Research, 9(2), 45-64.

Furlan, R., \& Petruccioli, A. (2016). Affordable Housing for Middle Income Expats in Qatar: Strategies for Implementing Livability and Built Form. ArchNet-IJAR: International Journal of Architectural Research, 10(3), 138-151.

Gaber, T. (2014). The Agency of Making and Architecture Education: Design-Build Curriculum in a New School of Architecture. ArchNet-IJAR: International Journal of Architectural Research, 8(3), 21-31.

García-Templado, G., \& Gharib, R. (2016). Advanced Architectural Descriptions of Al-Andalus Islamic Palaces: Development Of A Knowledge-Based Descriptive Framework. ArchNet-IJAR: International Journal of Architectural Research, 10(3), 113-137.

Gerards, S., De Ridder, R., \& De Bleeckere, S. (2015). Designing multigenerational dwelling: A workshop with four Flemish architecture firms. ArchNet-IJAR: International Journal of Architectural Research, $9(2), 20-30$.

Gharib, R. (2014). Sustainable Assessment Tool of Historic Centres: The Cases of Bath and Cambridge. ArchNet-IJAR: International Journal of Architectural Research, 8(1), 108-119.

Golden, S. M., Montgomery, I., \& Rikala, T. M. (2015). Public intentions for private spaces: Exploring architects' tactics to shape shared space in private-led residential development. ArchNet-IJAR: International Journal of Architectural Research, 9(2), 170-183.

Goulding, J. S., and Pour Rahimian, F. (2015). Design Creativity: Future Directions for Integrated Visualisation. ArchNet-IJAR: International Journal of Architectural Research, 9(3), 1-5.

Goulding, J. S., Rahimian, F. P., \& Wang, X. (2014). Virtual Reality-Based Cloud BIM Platform for Integrated AEC Projects. Journal of Information Technology in Construction (ITCON), 19(18), 308325.

Gur, E. (2014). The Effect of Physical and Environmental Factors of a "Child Development Centre" on a Centre's Selection. ArchNet-IJAR: International Journal of Architectural Research, 8(3), 136-148.

Horacek, M. (2014). Museum of Art versus the City as a Work of Art: A Case of the New Acropolis Museum in Athens. ArchNet-IJAR: International Journal of Architectural Research, 8(2), 47-61.

Huber, A. (2016). Research Utilization in the Design Decision Making Process. ArchNet-IJAR: International Journal of Architectural Research, 10(1), 4-25.

Jaiyeoba, B. E., Asojo, A. O., and Amole, B. (2017). The Yoruba Vernacular as a Paradigm for Low-Income Housing: Lessons from Ogbere, Ibadan, Nigeria. ArchNet-IJAR: International Journal of Architectural Research,11(1), 101-118.

Jamaludin, A. A., Hussein, H., Keumala, N., \& Ariffin, A. R. M. (2015). The Dynamics of Daylighting at a Residential College Building with the Internal Courtyard Arrangement. ArchNet-IJAR: International Journal of Architectural Research, 9(3), 147-164.

Kalb, J. (2014). Life in Design: Christopher Alexander and the Nature of Order. ArchNet-IJAR: International Journal of Architectural Research, 8(2), 94-98

Khan, M. A. and Loke, L. (2017). Locative Media Interventionism: A Conceptual Framework for Critical Review of Augmented Reality Applications in the Participatory Spatial Design Context. ArchNetIJAR: International Journal of Architectural Research,11(1), 181-209. 
Khuzzan,S. M. S., Goulding, J. S., \& Pour Rahimian, F. (2015). Purposive teaching styles for transdisciplinary AEC education: A diagnostic learning styles questionnaire. ArchNet-IJAR: International Journal of Architectural Research, 9(2), 98-112.

Kim, K., \& Steinfeld, E. (2016). An Evaluation of Stairway Designs Featured in Architectural Record Between 2000 and 2012. ArchNet-IJAR: International Journal of Architectural Research, 10(1), 96112.

Kim, M. J., Park, S. Y., \& Wang, X. (2015). A Conceptual Framework of Immersive Shared Environments Emphasizing Social Interaction. ArchNet-IJAR: International Journal of Architectural Research, 9(3), 45-52.

Lawrence, R. J. (2008). Rethinking Residential Mobility: An Interdisciplinary Interpretation. ArchNet-IJAR: International Journal of Architectural Research, 2(1), 70-83.

Maftei, L., \& Harty, C. (2015). Designing in Caves: Using Immersive Visualisations in Design Practice. ArchNet-IJAR: International Journal of Architectural Research, 9(3), 53-75.

Malhis, S., \& Al-Nammari, F. (2015). Interaction between internal structure and adaptive use of traditional buildings: Analyzing the heritage museum of Abu-Jaber, Jordan. ArchNet-IJAR: International Journal of Architectural Research, 9(2), 230-247.

Martin, C. (2014). Implementation of Evidence-Based Design (EBD) by Non-Healthcare Design Practitioners. ArchNet-IJAR: International Journal of Architectural Research, 8(3), 165-180.

Maturana, B. C. (2014). How Spike and the Slumdweller Find Reality in Design Studio Handouts: An Exploration of Reality in the Design Studio. ArchNet-IJAR: International Journal of Architectural Research, 4(2/3), 158-173.

Mclntyre, L. J. and Harrison, I. R. (2017). The Effects of Built Environment Design on Opportunities for Wellbeing in Care Homes. ArchNet-IJAR: International Journal of Architectural Research,11(1), 138156.

Meagher, M. (2014). Responsive Architecture and the Problem of Obsolescence. ArchNet-IJAR: International Journal of Architectural Research, 8(3), 95-104.

Megahed, N. (2014). Heritage-Based Sustainability in Port Said: Classification of Styles and Future Development. ArchNet-IJAR: International Journal of Architectural Research, 8(1), 94-107.

Megahed, N. A. (2015). Towards a Theoretical Framework for HBIM Approach in Historic Preservation and Management. ArchNet-IJAR: International Journal of Architectural Research, 9(3), 129-146.

Mehaffy, M. (2014). Counting Urban Carbon: Effective Modelling of Resource-Efficient Urban Design Decisions under Uncertain Conditions. ArchNet-IJAR: International Journal of Architectural Research, 8(2), 20-35.

Michl, J. (2014). A Case against the Modernist Regime in Design Education. ArchNet-IJAR: International Journal of Architectural Research, 8(2), 36-46.

Mohareb, N. (2016). Searching For Urban Patterns; an Assessment of Historic Edges and Its Surrounding Context: Historic Cairo as a Case Study. ArchNet-IJAR: International Journal of Architectural Research, 10(2), 67-86.

Montellano, A. S. (2015). Housing flexibility by spatial indeterminacy: The case of the Casa de las Flores in Madrid. ArchNet-IJAR: International Journal of Architectural Research, 9(2), 4-19.

Mostafa, M. (2014). Architecture for Autism: Autism ASPECTSS TM in School Design. ArchNet-IJAR: International Journal of Architectural Research, 8(1), 143-158.

Nia, E., Abd Rahman, N., \& Yunus, M. (2014). Roofs Functions in Vernacular Residential Buildings: Case Study in Kashan, Iran ArchNet-IJAR: International Journal of Architectural Research, 8(3), 251-265.

Oktay, D., \& Bala, H. A. (2015). A holistic research approach to measuring urban identity: Findings from Kyrenia area study. ArchNet-IJAR: International Journal of Architectural Research, 9(2), 201-215.

Othman, Z., Buys, L., \& Aird, R. (2014). Observing Privacy, Modesty and Hospitality in the Home Domain: Three Case Studies of Muslim Homes in Brisbane, Australia. ArchNet-IJAR: International Journal of Architectural Research, 8(3), 266-283.

Panda, S., Chakraborty, M., and Misra, S. K. (2017). Evaluation of India's Urban Social Sustainable Development Using a Composite Index. ArchNet-IJAR: International Journal of Architectural Research,11(1), 157-180.

Park, S., \& Kim, I. (2015). BIM-Based Quality Control for Safety Issues in the Design and Construction Phases. ArchNet-IJAR: International Journal of Architectural Research, 9(3), 110-128. 
Peschardt, K., \& Stigsdotter, U. (2014). Evidence for Designing Health Promoting Pocket Parks. ArchNetIJAR: International Journal of Architectural Research, 8(3), 149-164.

Preiser, W. F. E. (2008). Universal Design: From Policy to Assessment Research and Practice. ArchNetIJAR: International Journal of Architectural Research, 2(2), 78-93.

Preiser, W. F. E. and Wang, X. (2008). Quantitative (GIS) and Qualitative (BPE) Assessments of Library Performance. ArchNet-IJAR: International Journal of Architectural Research, 2(1), 212-231.

Preiser, W. F. E., Verderber, S. and Battisto, D. (2009). Assessment of Health Center Performance: Toward the Development of Design Guidelines. ArchNet-IJAR: International Journal of Architectural Research, 3(3), 21-44.

Ramzy, N. S. (2015). Sustainable spaces with psychological values: Historical architecture as reference book for biomimetic models with biophilic qualities. ArchNet-IJAR: International Journal of Architectural Research, 9(2), 248-267.

Rapoport, A. (2008). Some Further Thoughts on Culture and Environment. ArchNet-IJAR: International Journal of Architectural Research, 2(1), 16-39.

Rashid, M., \& Bartsch, K. (2014). Historical Fabulation: A Framework to Rethink the Islamic Architecture outside Islamic World. ArchNet-IJAR: International Journal of Architectural Research, 8(1), 120-132.

Raviz, S.R.H., Eteghad, A. N., Guardiola, E. U. \& Aira, A. (2015). Flexible housing: The role of spatial organization in achieving functional efficiency. ArchNet-IJAR: International Journal of Architectural Research, 9(2), 65-76.

Ryan, C., Browning, W., Clancy, J., Andrews, S., \& Kallianpurkar, N. (2014). Biophilic Design Patterns: Emerging Nature-Based Parameters for Health and Well-Being in the Built Environment. ArchNetIJAR: International Journal of Architectural Research, 8(2), 62-76.

Sahabuddin, M.F.M \& Gonzalez-Longo, C. (2015). Traditional values and their adaptation in social housing design: Towards a new typology and establishment of 'Air House' standard in Malaysia. ArchNetIJAR: International Journal of Architectural Research, 9(2), 31-44.

Salama, A. M. (2014). Interrogating the Practice of Image Making in a Budding Context. ArchNet-IJAR: International Journal of Architectural Research, 8(3), 74-94.

Salama, A. M. and Azzali, S. (2015). Examining Attributes of Urban Open Spaces in Doha. Proceedings of the Institution of Civil Engineers - Urban Design and Planning, 168 (2), 57-87 http://dx.doi.org/10.1680/udap.14.00011

Salama, A. M. and Crosbie, M. J. (2010). Design Education: Explorations and Prospects for a Better Built Environment. ArchNet-IJAR: International Journal of Architectural Research, 4(2-3), 10-18.

Salama, A. M., \& Grichting, A. K. (2015). Flexible housing: The role of spatial organization in achieving functional efficiency. ArchNet-IJAR: International Journal of Architectural Research, 9(2), 113-136.

Salama, A. M., Khalfani, F., Al-Maimani, A. (2013). Experiential Assessment of Urban Open Spaces in Doha. Open House International, 38(4) 47-57.

Salama, A. M., Wiedmann, F., Thierstein, A., \& Al Ghatam, W. (2016). Knowledge Economy as an Initiator of Sustainable Urbanism in Emerging Metropolises: The Case of Doha, Qatar. ArchNet-IJAR: International Journal of Architectural Research, 10(1), 274-324.

Salat, S., Bourdic, L., \& Labbe, F. (2014). Breaking Symmetries and Emerging Scaling Urban Structures: A Morphological Tale of 3 Cities: Paris, New York and Barcelona. ArchNet-IJAR: International Journal of Architectural Research, 8(2), 77-93.

Salingaros, N. A. (2014). Complexity, Patterns and Biophilia. ArchNet-IJAR: International Journal of Architectural Research, 8(2), 5-7.

Salingaros, N. A. and Masden II, K. G. (2008). Intelligence-Based Design: A Sustainable Foundation for Worldwide Architectural Education. ArchNet-IJAR: International Journal of Architectural Research, 2(1), 129-188.

Sanoff, H. (2008). Multiple Views of Participatory Design. ArchNet-IJAR: International Journal of Architectural Research, 2(1), 57-69.

Shehada, Z. M., Ahmad, Y., Yaacob, N. M., \& Keumala, N. I. (2015). Developing methodology for adaptive re-use: Case study of heritage buildings in Palestine. ArchNet-IJAR: International Journal of Architectural Research, 9(2), 216-229.

Shih, Y. T., Sher, W. D., \& Taylor, M. (2015). Understanding Creative Design Processes by Integrating Sketching and CAD Modelling Design Environments: A Preliminary Protocol Result from Architectural Designers. ArchNet-IJAR: International Journal of Architectural Research, 9(3), 76-91. 
Sibley, M. (2008). Editorial: Special Issue On Traditional Public Baths - Hammams - in the Mediterranean. ArchNet-IJAR: International Journal of Architectural Research, 2(3), 10-16.

Skayannis, P., \& Kyratzakos, A. (2015). High flights and hard landings: The adventures of planning for the regeneration of Thessaloniki's derelict western entrance. ArchNet-IJAR: International Journal of Architectural Research, 9(2), 184-200.

Smith, M. (2014). Housing in Premodern Cities: Patterns of Social and Spatial Variation. ArchNet-IJAR: International Journal of Architectural Research, 8(3), 207-222.

Soetanto, R., Childs, M., Poh, P. S. H., Austin, S., Glass, J., Adamu, Z. A., and MacKenzie, H. (2015). Key Success Factors and Guidance for International Collaborative Design Projects. ArchNet-IJAR: International Journal of Architectural Research, 9(3), 6-25.

Tezgelen, D., \& Karaman, O. (2014). Evaluation of User Comfort in Tunnel Formwork Housing Areas: Izmir as a Case Study. ArchNet-IJAR: International Journal of Architectural Research, 8(1), 78-93.

Ujang, N. (2014). Place Meaning and Significance of the Traditional Shopping District in the City Centre of Kuala Lumpur, Malaysia. ArchNet-IJAR: International Journal of Architectural Research, 8(1), 66-77.

Verderber, S. (2014). Exploring Healthcare Architecture through the Medium of Film: Motives and Techniques. ArchNet-IJAR: International Journal of Architectural Research, 8(1), 29-49.

Verderber, S. (2016). Learning from Commercial Vernacular Building Types: A North American Case Study. ArchNet-IJAR: International Journal of Architectural Research, 10(2), 22-37.

von Meding, J. Mackee, J., and Gajendran, T. (2013). Editorial: Built Environment Perspectives on PostDisaster Reconstruction. ArchNet-IJAR: International Journal of Architectural Research, 7(3), 8-13.

Wang, R., Newton, S., \& Lowe, R. (2015). Experiential Learning Styles in the Age of a Virtual Surrogate. ArchNet-IJAR: International Journal of Architectural Research, 9(3), 92-109.

Yuan, X., Anumba, C. J., \& Parfitt, M. K. (2015). Review of the Potential for a Cyber-Physical System Approach to Temporary Structures Monitoring. ArchNet-IJAR: International Journal of Architectural Research, 9(3), 26-44.

Zagora, N., \& Samic, D. (2014). Sarajevo Lost in Transition? Ideologies and Their Representational Spaces. ArchNet-IJAR: International Journal of Architectural Research, 8(1), 159-170.

Zhang, D. (2016). Juer Hutong New Courtyard Housing In Beijing: A Review from the Residents' Perspective. ArchNet-IJAR: International Journal of Architectural Research,10(2), 166-191.

\section{AUTHORS}

Ashraf M. Salama, Professor

Professor and Head of Department of Architecture

University of Strathclyde, Glasgow, UK

ashraf.salama@strath.ac.uk

Adel M. Remali, Dr

Research Associate

Department of Architecture

University of Strathclyde, Glasgow, UK

adel.remali@strath.ac.uk

Farzad Pour Rahimian, Dr

Senior Lecturer in Building Information Management

Department of Architecture

University of Strathclyde, Glasgow, UK

farzad.rahimian@strath.ac.uk 